\title{
POSITIVISMO, PLURALISMO JURÍDICO E O PARADIGMA EMERGENTE: A TEORIA DA COMPLEXIDADE E SEUS OBSTÁCULOS EPISTEMOLÓGICOS
}

\section{Gilsilene Passon Picoretti Francischetto ${ }^{1}$ Lucas Kaiser Costa ${ }^{2}$}

\section{RESUMO}

O presente artigo tem como pretensão investigar quais seriam os obstáculos, teóricos e práticos, impostos e enfrentados pela teoria da complexidade no paradigma emergente, tendo como lócus de observação o olhar a partir do direito. Parte-se, para tanto, da análise da transição paradigmática vivenciada entre a modernidade e o modelo emergente, verificando, a partir do exame sobre os referenciais teóricos, o paradigma cientificista e o contexto de surgimento da teoria da complexidade, bem como, a emergência do "complexo" e a necessidade de rompimento com o paradigma em crise, delineando, ainda, os aspectos gerais da teoria que fundamenta essa passagem. Propõe-se, então, contribuir com o debate, investigando teórica e dialeticamente, a relação entre direito e racionalidade e os caminhos que a partir daí se desenham, para se concluir pela existência de dois obstáculos: o positivismo jurídico, enquanto obstáculo teórico, operando na redução da complexidade do direito; e, o pluralismo jurídico, enquanto obstáculo epistemológico, negando a primazia do Estado na produção jurídica. A conformação de ambos os obstáculos são as barreiras epistemológicas que se colocam na emergência do paradigma emergente.

Palavras-chave: teoria da complexidade - paradigma emergente - positivismo - pluralismo jurídico - obstáculos epistemológicos

\section{INTRODUÇÃO}

A teoria do conhecimento aponta, comumente, três formas de saber como meios capazes de explicar os fenômenos do mundo e as coisas da vida, seriam elas, a teologia, a filosofia e a ciência. É

\footnotetext{
${ }^{1}$ Pós-Doutora pelo Centro de Estudos Sociais da Universidade de Coimbra. Doutora em Direito pela Universidade Gama Filho (UGF). Pesquisadora-líder do grupo de pesquisas "Invisibilidade Social e Energias Emancipatórias em Direito Humanos", inscrito no CNPq. Professora do PPGD na Faculdade de Direito de Vitória. Faculdade de Direito de Vitória - FDV, Espírito Santo - Brasil. ORCID iD: Lattes: E-mail: gilsilenepasson@uol.com.br

${ }^{2}$ Doutorando em Direitos e Garantias Fundamentais pela Faculdade de Direito de Vitória (FDV). Mestre em Direito pela mesma instituição. Pesquisador do grupo de pesquisas "Invisibilidade Social e Energias Emancipatórias em Direito Humanos", inscrito no CNPq. Professor na Faculdade Multivix. Faculdade de Direito de Vitória - FDV, Espírito Santo - Brasil. ORCID iD: Lattes: E-mail: lucas-kaiser@hotmail.com
} 
bem verdade, porém, que em determinado momento da história se rompeu com as explicações teológicas e filosóficas, verificando-se a supremacia da forma de saber científica. Dá-se a esse momento o nome de modernidade.

A modernidade, por sua vez, tem como característica marcante uma racionalidade calcada na razão humana. Vale dizer, rompe-se com o modelo anterior - pré-moderno - e se estabelece o homem e o atendimento das suas necessidades como fim último. Daí a busca incansável pela verdade, pelo progresso e pelo controle e dominação da natureza, como formas de instrumentalizar esse sucesso.

Essa busca pela verdade não se traduziu, contudo, numa busca por qualquer verdade, senão pela verdade da ciência, como única capaz de dar uma resposta satisfatória - eis que pretensamente precisa - às angústias humanas.

Passou-se, assim, a se cientificizar o mundo, na medida em que as respostas eram encontradas apenas dentro dessa forma de conhecimento, o saber científico. Atribui-se a esse paradigma o nome de positivismo, que, se espraiando pelas diversas áreas do conhecimento, veio a refletir inclusive no direito - positivismo jurídico.

Eram as próprias características do positivismo cientificista que justificavam sua dominância, eis que tinha como pretensão reduzir a possibilidade de questionamentos sobre os resultados de suas investigações, o que se traduzia na diminuição de questionamentos sobre a sua própria hegemonia.

Entretanto, foi seu próprio avanço que acabou por esgarçar sua crise, na medida em que expôs suas fragilidades, limitações e insuficiências. Vale dizer, avançou-se tanto a partir do paradigma científico que alguns de seus pilares foram fragilizados, como as ideia de certeza, precisão e infalibilidade, em que a própria ciência demonstrou possuir em seu âmago a presença da incerteza, da imprecisão e da falibilidade.

O que se observa, portanto, são verdadeiras disfunções do paradigma positivista cientificista, na medida em que, tentando dominar a realidade, enquadrando-a no seu bojo, reduziu-a drasticamente àquilo que entendia hegemonicamente enquanto compreensão perfeita e acabada dos fenômenos e das coisas da vida.

Disfunções essas que não ficaram adstritas somente à ciência, uma vez que, notadamente a partir do século XVIII, com a consolidação dos Estados Modernos - após o advento da Revolução 
Francesa, em 1789 -, verificou-se a ampliação da influência do espectro positivista para outros campos do conhecimento, dentre os quais o direito.

Notou-se, assim, a complexificação da vida e das relações sociais, que, por sua vez, não foram acompanhadas pelo paradigma hegemônico científico, instrumentalizado pela racionalidade moderna. Quer dizer, as respostas dadas a partir dessa racionalidade científica já não mais atendiam às demandas sociais em sua plenitude.

Demandou-se, então, a partir da crise paradigmática do positivismo cientificista, alternativas que superassem o viés moderno, calcado nessa racionalidade instrumental, e que promovessem um olhar que conformasse a perspectiva científica à realidade atual.

E é exatamente nesse contexto em que se insere o paradigma da complexidade, hoje experimentando, enquanto proposta de um olhar que reconheça a importância da ciência, mas também enxergue suas limitações, promovendo a partir daí um caminhar que a supere, tendo-a como pressuposto. É a utilização da ciência para além dela mesma, cotejando-a, sobretudo, com aquilo que ela própria deixou de lado, o sujeito.

Esse processo, porém, não obstante emergente, encontra evidentes obstáculos epistemológicos, sociais, culturais, políticos, econômicos, entre outros, como não poderia ser diferente, na medida em que forças contrapostas se embatem visando, de um lado, a manutenção do status quo, e, de outro lado, a superação do modelo dominante.

Assim como, essa nova perspectiva se apresenta, por si só, também como obstáculo, na medida em que demanda um esforço social ativo de internalização, ante as mudanças que provoca. Nota-se, portanto, a emergência de um paradigma que, ao passo que enfrenta obstáculos, também os impõe. Trata-se, pois, de uma tarefa duplamente dificultosa.

Nesta perspectiva, portanto, surge como elemento motivador da realização deste estudo a seguinte indagação: Tendo como lócus de observação o olhar a partir do direito, quais seriam os obstáculos epistemológicos - teóricos e práticos - impostos e enfrentados pela teoria da complexidade no paradigma emergente?

Noutro caminhar, como objetivos específicos pretende-se: primeiramente, descrever o paradigma cientificista e o contexto de surgimento da teoria da complexidade; num segundo momento, 
analisar a emergência do "complexo" e a necessidade de rompimento com o paradigma em crise; e, finalmente, delinear os aspectos gerais da teoria da complexidade.

Sendo assim, propõe-se o desenvolvimento do presente estudo através de uma pesquisa teórica, vale dizer, partir-se-á do exame a partir de referenciais teóricos que abordem os temas trabalhados, propondo-se um diálogo e uma contraposição de ideias, ampliando-se o debate e os argumentos para o discurso, visando a construção provisória de um novo saber ou uma nova concepção do tema proposto, sem a pretensão de esgotá-lo.

\section{PARADIGMA POSITIVISTA CIENTIFICISTA E RACIONALIDADE MODERNA: O CONTEXTO DE SURGIMENTO DA TEORIA DA COMPLEXIDADE}

A partir da passagem da pré-modernidade para a modernidade - com a superação da teologia e da filosofia, em detrimento do conhecimento científico, enquanto parâmetro de verdade -, juntamente com a consolidação dos Estados modernos - após a Revolução Francesa, em 1789 -, marcou-se a formação do paradigma moderno, vale dizer, do "modelo científico de verdade, aceito e predominante em determinado momento histórico" (KUHN, 1975, p. 218), ou, em outras palavras, da teia de pressupostos políticos, econômicos, sociais e culturais que informaram o período.

Assim, os pilares que embasaram e sustentaram a modernidade foram, de um lado, o conhecimento científico, e, de outro lado, o direito moderno estatal - este, inclusive, possibilitado pelo própria ciência moderna. E isso porque, enquanto o primeiro buscou informar os critérios de verdade e de falsidade para as explicações sobre a vida humana de uma maneira geral, o segundo, por sua vez, estabeleceu a forma de organização dos Estados modernos, bem como a própria regulação social.

Saiu-se, então, de um momento pré-moderno, fortemente marcado pela influência do "divino"3 na explicação dos acontecimentos do mundo, para um momento moderno, em que essas mesmas explicações passaram a se basear na razão. E isso porque, a teologia e a filosofia mostraram-se incapazes de atestar a verdade ou a falsidade acerca das coisas do mundo e da vida propriamente.

Essa racionalidade, por sua vez, se pautou justamente na ciência - a racionalidade científica , uma vez que se acreditou que essa forma de conhecimento seria capaz de responder com precisão às indagações humanas. Centrou-se, assim, no homem e não mais na figura divina; ocasião essa que

\footnotetext{
${ }^{3}$ Tanto no campo da teologia, como na área da própria filosofia, a influência da figura divina era percebida.
} vol.13, nº.01, Rio de Janeiro, 2020.pp.123-147 
marcou o rompimento com a Idade Média, caracterizando-se, então, a passagem da pré-modernidade para a modernidade.

Esse modelo de racionalidade moderna foi constituído a partir da revolução científica ${ }^{4}$, no século XVI, tendo perdurado pelos séculos subsequentes, sobretudo os séculos XVII e XVIII, e tem como característica marcante a separação ${ }^{5}$ entre ciência, filosofia e teologia, tendo ficado incumbido à primeira - ciência moderna -, conforme mencionado, o "monopólio da distinção universal entre o verdadeiro e o falso" (SANTOS, 2007, p. 03).

Noutras palavras, coube à ciência moderna não apenas a primazia da verdade, mas também o papel de protagonismo epistemológico como única forma de conhecimento credível, de modo que, em sentido contrário, todo conhecimento que não se pautava nos métodos científicos ${ }^{6} \mathrm{e}$ em seus preceitos era rechaçado. Daí apontar-se, por exemplo, o senso comum como um dos grandes vilões da ciência (SANTOS, 2010b).

Ocorre, todavia, que o cientificismo característico da racionalidade moderna não ficou adstrito apenas às ciências da natureza ou às matemáticas, tendo havido a tentativa de transposição das leis dessas ciências para o estudo da própria sociedade ${ }^{7}$. E é aí que se insere o direito; vale dizer, é nesta perspectiva que o direito tornou-se também um dos pilares da modernidade.

Observa-se, assim, na modernidade, não apenas um privilégio à ciência e ao direito, mas um privilégio ao próprio Estado moderno, bem como ao seu viés econômico, notadamente como fonte da própria ciência e, principalmente, do próprio direito, de modo que a racionalidade moderna, então, passou a lhe servir e a justificar suas próprias pretensões.

Neste sentido, o que se nota é que a modernidade construiu seu “modus" calcado em uma razão técnica instrumental, decorrente de um racionalismo iluminista, que simplesmente instrumentalizou as relações, quer dizer, tratou-se de uma racionalidade que vigorava como instrumento e meio para justificar qualquer ação.

\footnotetext{
${ }^{4}$ Foram centrais na revolução científica: Copérnico, Galileu, Newton, Bacon e Descartes (SANTOS, 2010b, p. 22).

${ }^{5}$ Destacam-se dentre as razões para essa separação: o advento do renascimento cultural; o surgimento da imprensa; e a reforma protestante - este último, inclusive, foi pilar fundamental no desenvolvimento da ciência, na medida em que questionou os dogmas religiosos outrora impostos.

${ }^{6}$ Os métodos científicos exerceram - e ainda exercem - papel fundamental para a ciência, e, via de consequência, para a própria modernidade, notadamente porque possibilitaram atestar a verdade sobre as coisas da vida através da experimentação e da observação, sobretudo nas ciências naturais e exatas.

${ }^{7}$ Foi no século XVIII, com o iluminismo, que se criaram as condições para a emergência das ciências sociais no século XIX (SANTOS, 2010b, p. 33), ocasião em que se consolidou o positivismo.
} 
Deste modo, ao invés da proposta de uma racionalidade "salvadora" das sociedades do Estado moderno, notadamente no sentido de emancipação para o homem e superação das crendices medievais, a razão imperante acabou por subverter essa pretensão inicial, retroalimentando-se de um sistema econômico moderno que lhe deu guarida.

Antônio Carlos Wolkmer (2002, p. 02), ao se debruçar sobre o tema, aduz que essa racionalização "define-se como racionalidade instrumental positiva que não liberta, mas reprime, aliena e coisifica o homem”. Razão essa fruto da modernidade liberal-burguesa e do sistema econômico capitalista que a suportava.

Para o teórico português Boaventura de Sousa Santos (2007b, p. 25), na esteira de Gottfried Leibniz, essa racionalidade moderna é uma "racionalidade indolente", eis que "se considera única, exclusiva, e que não se exercita o suficiente para poder ver a riqueza inesgotável do mundo". Noutras palavras, essa razão indolente compreende a sua própria epistemologia hegemônica enquanto compreensão total do mundo; vale dizer, fora dela não há conhecimento. Isso, inevitavelmente, ocasiona um enorme desperdício de experiências.

Verifica-se, portanto, uma verdadeira crise do paradigma dominante, que não é apenas profunda, mas irreversível, embora ainda não se saiba como será esse outro momento vindouro (SANTOS, 2010, p. 40) ${ }^{8}$. Essa complicação em se precisar o novo paradigma também foi verificada por Wolkmer (2002, p. 01), segundo o qual há "uma certa dificuldade em encontrar-se um novo parâmetro de verdade diante da crise de fundamento que vive a sociedade hodierna"

E isso porque,

as verdades teológicas, metafísicas e racionais que sustentaram durante séculos as formas de saber e de racionalidade dominantes não conseguem mais responder inteiramente às inquietações e às necessidades do presente estágio de desenvolvimento da modernidade humana. Os modelos culturais, normativos e instrumentais que fundamentaram o mundo da vida, a organização social e os critérios de cientificidade tornaram-se insatisfatórios e limitados (WOLKMER, 2002, p. 01).

\footnotetext{
${ }^{8}$ Boaventura de Sousa Santos (2006) assevera que, embora não se possa precisar o paradigma emergente, que ele seja o paradigma de um "conhecimento prudente para uma vida decente". Edgar Morin (2011), por sua vez, fala em se sair do "paradigma simplificador" para o "paradigma da complexidade".

${ }^{9}$ Embora se utilize de outra terminologia, o próprio Wolkmer (2002, p. 02) caminha na mesma esteira que Morin, ao aduzir que esse novo momento paradigmático marca-se, justamente, pela complexidade do mundo e das relações sociais, de uma maneira geral.
} 
São diversas as condições para a crise do paradigma dominante, dentre condições teóricas e sociais, como, por exemplo, o fato de que a identificação das limitações desse paradigma é fruto do próprio avanço científico que as expôs, ou, ainda, a própria relativização do rigor das leis, sobretudo matemáticas e físicas - outrora pretensamente inquestionáveis -, ante a interferência humana no objeto e que antes respondiam às questões do mundo e agora não mais o fazem, entre outros (SANTOS, 2010b).

De qualquer modo, fato é que o que se esgarça é a inegável descrença no modelo hegemônico vigente, o paradigma cientificista. E é exatamente nesse contexto que surge enquanto proposta de superação do modelo dominante, o paradigma da complexidade.

\section{A EMERGÊNCIA DO COMPLEXO: A NECESSIDADE DE ROMPIMENTO COM O PARADIGMA SIMPLIFICADOR}

Demonstrou-se, acima, a relação indissociável existente entre a consolidação do paradigma moderno, calcado numa racionalidade iluminista, e a emergência do conhecimento científico, fundado na corrente positivista, enquanto parâmetro de verdade para a explicação das coisas do mundo.

Observou-se, desta forma, uma perseguição obsessiva da ciência pela verdade, vale dizer, um esforço de se buscar as explicações primeiras sobre todas as coisas, comprovando empiricamente os resultados obtidos. Noutras palavras, tentou-se tirar das mãos de Deus - a quem, na pré-modernidade, eram atribuídas essas causas - e colocar na mão dos homens ${ }^{10}$ as ferramentas necessárias para que fosse possível dominar a realidade.

Essa pretensão de domínio se deu na tentativa de redução da complexidade do real, para que, então, os fenômenos se tornassem compreensíveis; vale dizer, a ciência passou a operar visando tornar simples o que, sem ela, parecia complexo, desorganizado, caótico ${ }^{11}$. Deste modo, o paradigma

\footnotetext{
${ }^{10}$ Cumpre esclarecer, entretanto, que não eram dadas a qualquer homem sobreditas ferramentas, mas apenas aos homens da ciência.

${ }^{11}$ É bem verdade que essa busca pela simplificação dos fenômenos, visando se alcançar as causas primeiras, ajudou sobremaneira a ciência a se desenvolver. A obsessão pelo "simples" e por uma "lei única" possibilitou saltos epistemológicos qualitativos e quantitativos fantásticos. Veja, por exemplo - na esteira do exemplo trazido por Edgar Morin (2011, p. 60) -, a busca pelo elemento primordial, constituidor do universo. A ciência conhecia a molécula, acreditando-a como sendo esse elemento. Os avanços científicos, contudo, revelaram o átomo, que, por sua vez, mostrou-se complexo, eis que formado por um núcleo e elétrons; esses, então, divisíveis teoricamente em quarks, e assim por diante. O que se depreende, desta maneira, é que a perseguição pelo simples acaba indo no sentido contrário às pretensões iniciais, tendo em vista que expõe o complexo, apresentando-o.
} 
moderno, cientificizante, além de indolente (SANTOS, 2011), também pode ser qualificado daquilo que Edgar Morin (2011, p. 59) chama de "paradigma simplificador".

Explica o teórico francês que o paradigma simplificador "é um paradigma que põe ordem no universo, expulsa dele a desordem. A ordem se reduz a uma lei, a um princípio" (MORIN, 2011, p. 59); almeja-se, assim, a causas determinísticas, a lei universal, não se percebendo que a redução da complexidade, conforme pretendido pelo paradigma simplificador, representa a redução do próprio mundo.

E isso porque, um pensamento que se pretende simplificador acaba por mutilar a realidade, uma vez que ignora a multiplicidade dos fenômenos e a complexidade inerente aos mesmos. E, como aduz Morin (2011, p. 15) "um pensamento mutilador conduz necessariamente a ações mutilantes"12.

"A simplicidade vê o uno, ou o múltiplo, mas não consegue ver que o uno poder ser ao mesmo tempo múltiplo" (MORIN, 2011, p. 59), ou, dito de outro modo, a simplicidade é incapaz de perceber que "o todo está na parte, que [, por sua vez,] está no todo"13 (MORIN, 2011, p. 75), e isso, invariavelmente, acaba por reduzir as experiências do mundo, uma vez que se opta por ativamente produzi-las como inexistentes, desperdiçando-as, como bem previu Santos $(2011)^{14}$.

Tal constatação, da simplificação operada pelo paradigma moderno, não se verifica apenas na ciência, mas também no outro pilar da modernidade, vale dizer, se verifica também no campo do direito. E isso porque a pretensão do direito é a de, justamente, reduzir a complexidade do real, enquadrando todo e qualquer caso, por mais múltiplo que possa se mostrar, dentro de uma "caixinha", a norma jurídica. Trata-se da famigerada subsunção do fato à norma, como se houvesse uma correspondência necessária entre ambos ${ }^{15}$.

\footnotetext{
12 Morin (2011, p. 59) traz o exemplo do próprio homem para demonstrar a sua verificação. E isso porque, aduz o francês, o homem é ao mesmo tempo um ser biológico e cultural; todavia, no paradigma da simplificação, essas duas realidades são separadas, estudando-se a primeira no campo da biologia e a segunda nas ciências humanas e sociais. Essa separação, contudo, ao passo em que quer reduzir a complexidade, mutila o conhecimento, tendo em vista que não se concebe a existência de uma sem a outra, eis que uma é a outra ao mesmo tempo.

${ }^{13}$ Faz Morin clara referência a um dos motes científicos modernos, fruto do pensamento cartesiano, no sentido de decompor o todo em partes para que cada uma delas seja mais bem compreendida. Perde-se nesta ação, contudo, a própria ideia do todo, e, mais - e ainda pior -, a inter-relação existente entre o todo e a parte, e entre a parte e o todo, eis que se compõem mutuamente e indissociavelmente. Daí a ideia de complexidade e da impossibilidade de um pensamento reducionista.

${ }^{14}$ Observa-se, assim, aliás, a aproximação teórica dos dois autores - Boaventura de Sousa Santos e Edgar Morin -, notadamente na descrição do paradigma moderno e na cegueira por ele operada, assim como na necessidade de se transpô-lo, conforme se detalhará a seguir.

${ }^{15}$ Em realidade, por evidente, essa subsunção é mera ficção; vale dizer, aparam-se as arestas do caso concreto, fazendo-o se adequar àquela determinada norma jurídica. Reduz-se, assim, novamente, a complexidade.
} 
A simplificação do direito moderno pelo paradigma simplificador também se opera no momento em que é entregue nas mãos apenas do Estado o poder de dizê-lo, ou seja, a partir do momento em que o direito oficial é apenas o direito estatal, invisibilizando-se - e, via de consequência, reduzindo a complexidade do mundo -, toda e qualquer ordem pretensamente jurídica.

Nota-se, deste modo, uma verdadeira crise do paradigma moderno, caracterizada também pela obsessão da simplificação, vivendo-se, então, nos dias atuais, uma transição paradigmática, quer dizer, um esgotamento do modelo hegemônico da modernidade, que não mais atende as demandas sociais, para um paradigma novo, emergente, ainda se delineando, mas que se identifica pelo descontentamento com o arquétipo anterior.

Nesta perspectiva, propõe Morin (2011), enquanto concepção ideal, a passagem do paradigma simplificador para um "paradigma da complexidade", ou seja, para um modelo que substitua a forma de raciocínio moderna - disjuntiva e reducionista -, para uma racionalidade que contemple em seu bojo o paradoxo do uno e do múltiplo, de modo que um se insira dentro do outro, constituindo-se mútua e heterogeneamente, através de uma inseparável associação.

E isso porque, para Edgar Morin (2011), a complexidade é "o tecido de acontecimentos, ações, interações, retroações, determinações, acasos, que constituem nosso mundo fenomênico", apresentando-se com "os traços inquietantes do emaranhado, do inextricável, da desordem, da ambiguidade, da incerteza".

Dito de outro modo, a proposta do teórico francês perpassa pela negação da pretensão positivista - tanto do positivismo científico, como do positivismo jurídico - de lançar um olhar simplificador para os fenômenos do mundo, seja para os fenômenos naturais, como para os fenômenos sociais, culturais, econômicos, políticos, entre outros, tendo em vista que todos eles estão indissociavelmente conectados e se influenciam e se determinam mutuamente, de modo que qualquer tentativa de se separá-los para exame representa uma mutilação de sua ontologia e de sua epistemologia.

Esse rompimento, entretanto, do paradigma simplificador para o paradigma da complexidade não ocorre por si só, quer dizer, não representa o curso natural da história, mas demanda ações (ou mesmo inações) humanas. E isso porque, do mesmo modo que se produz ativamente a simplificação 
(MORIN, 2011), há que se produzir ativamente também o paradigma emergente. Daí a emergência da teoria da complexidade enquanto ferramenta capaz de promover, ou ao menos facilitar, essa transição.

\section{A TEORIA DA COMPLEXIDADE A PARTIR DE EDGAR MORIN}

Segundo Edgar Morin (2011, p. 09-10) faz-se necessário uma tomada de consciência radical. E isso porque, a falsa consciência da realidade não decorre da ausência de conhecimento, mas do seu modo de organização mutilador, incapaz de apreender a complexidade do real.

O conhecimento, para o teórico francês, opera por seleção de dados significativos e rejeição de dados não significativos: separa (distingue ou disjunta) e une (associa, identifica); hierarquiza (principal, secundário) e centraliza (em função de um núcleo de noções-chave). E é exatamente o paradigma cientificista que promove essas operações de organização do conhecimento (MORIN, 2011, p. 10).

Vive-se, então, sob o império dos princípios de disjunção, de redução e de abstração, cujo conjunto constitui o paradigma da simplificação. Esse paradigma permitiu avanços, mas escamoteou suas consequências nocivas. A forma de remediar essa disjunção foi uma outra simplificação: a redução do complexo ao simples (MORIN, 2011, p. 11).

“O pensamento simplificador é incapaz de conceber a conjunção do uno e do múltiplo. Ou ele unifica abstratamente ao anular a diversidade, ou, ao contrário, justapõe a diversidade sem conceber a unidade. Assim, chega-se à inteligência cega" (MORIN, 2011, p. 12) em que se ignora a própria ignorância.

Demanda-se, então, um pensamento complexo. E é a própria ciência que, visando a ordem, aponta para a complexidade (termodinâmica; microfísica; cosmos; etc.), uma vez que, sabendo-se da complexidade dos fenômenos naturais, torna-se evidente que os fenômenos antropossociais não poderiam responder a princípios menos complexos. A proposta, então, é a passagem do paradigma simplificador, que informa a organização do conhecimento de maneira disjuntiva e reducionista, para o paradigma da complexidade, que distingue sem disjungir, que associe sem reduzir (MORIN, 2011, p. 12).

Para que seja possível a emergência da complexidade, Morin (2011, p. 18) identifica duas brechas no quadro epistemológico da ciência clássica: a brecha microfísica e a brecha macrofísica. A 


\section{Quaestio Iuris}

vol. 13, nº 01 , Rio de Janeiro, 2020. pp. 123-147 DOI: $10.12957 /$ rqi.2020.39955

primeira revela a interdependência do sujeito e do objeto, a presença do acaso no conhecimento, a contradição lógica na descrição empírica. A segunda, por sua vez, une numa mesma entidade os conceitos até então heterogêneos de espaço e de tempo e quebra os conceitos a partir do momento em que eles eram transportados para além da velocidade da luz.

Deste modo, para se lidar com ambas as brechas, o teórico francês propõe a utilização da teoria dos sistemas. E isso porque, segundo o autor, num certo sentido toda realidade conhecida, desde o átomo até a galáxia, passando pela molécula, a célula, o organismo e a sociedade, pode ser concebida como sistema, isto é, associação combinatória de elementos diferentes (MORIN, 2011, p. 18).

Entretanto, não é qualquer sistema que se presta à complexidade, senão o sistema aberto, eis que permite a troca de matéria e energia com o exterior, ao contrário do sistema fechado, que sofre interação apenas de seu ambiente interno. A importância dessa concepção atine ao fato de que os sistemas vivos são sistemas abertos, que dependem de uma alimentação externa, não apenas material/energética, mas também organizacional/informacional.

Ao contrário do sistema fechado, no sistema aberto não há absoluto equilíbrio em seu meio interno, há desequilíbrio no fluxo energético que os alimenta, e, sem esse fluxo, haveria desordem organizacional. Esse desequilíbrio alimentador permite ao sistema manter-se em aparente equilíbrio, isto é, em estado de estabilidade e continuidade. O paradoxo reside no fato de que as estruturas permanecem as mesmas, ainda que os constituintes sejam mutantes (MORIN, 2011, p. 21).

Duas consequências, então, decorrem da ideia de sistema aberto: as leis de organização da vida não são de equilíbrio, mas de desequilíbrio; a inteligibilidade do sistema deve ser encontrada não apenas no próprio sistema, mas também na sua relação com o meio ambiente, e que essa relação não é de dependência, ela é constitutiva do sistema. A realidade está tanto no elo quanto na distinção entre sistema aberto e seu meio ambiente (MORIN, 2011, p. 22).

Essa desordem organizacional, então, inerente ao sistema aberto, traz em si mesma um princípio auto-eco-organizador ${ }^{16}$, que se consubstancia a partir de um elo, justamente, entre desorganização e (re)organização complexa, o que postula, por sua vez, uma lógica da complexidade.

\footnotetext{
${ }^{16}$ Exemplifica Morin (2011, p. 31) que, na máquina artefato há grande confiabilidade dos constituintes (como peças de um motor do carro), mas em seu conjunto a máquina é pouco confiável, uma pequena alteração nos constituintes faz o conjunto parar e não se auto-organiza, eis que depende de intervenção externa. Já a máquina viva, embora possua componentes pouco confiáveis, há grande confiabilidade do conjunto (moléculas que se degradam e morrem, mas se renovam, a tal ponto que um organismo resta idêntico a ele mesmo ainda que todos os constituintes se renovem).
} 
Para Morin (2011, p. 35), a complexidade, além de quantidades de unidades que interagem e se interferem, compreende também incertezas e indeterminações, aleatoriedade; num certo sentido sempre relação com o acaso. Mas não se reduz à incerteza, é a incerteza no seio da certeza; incerteza no seio de sistemas ricamente organizados. Ordem e acaso/desordem são inseparáveis. Resta desenvolvida assim, uma teoria, ou ao menos um caminho, para um pensamento complexo.

\subsection{O QUE MUDA NA COMPLEXIDADE? ANÁLISE A PARTIR DO LUGAR DO SUJEITO}

Mencionou-se outrora que as próprias características do positivismo cientificista justificaram sua dominância, de maneira a reduzir a possibilidade de questionamentos acerca da sua própria hegemonia. Dentre essas características se destaca a neutralidade, segundo a qual os procedimentos científicos obtêm seus resultados independentemente da subjetividade do investigador, uma vez que a verdade está sempre no objeto, cabendo ao pesquisador tão somente a descobrir.

Há, portanto, a partir da lógica cartesiana, uma separação marcante entre sujeito e objeto, em que o segundo ocupa lugar privilegiado em relação ao primeiro, que, por sua vez, assume papel de mero coadjuvante, ante a pretensão de objetividade ${ }^{17}$ da ciência, que lhe conferia possibilidade de se chegar à verdade.

A neutralidade, então, subjazeria da objetividade, na medida em que a característica desta dispõe que "o sujeito conhecedor não deve influenciar [no] objeto de modo algum" (DIONNE, 1999, p. 27). Vale dizer, sendo objetiva por si só, não haveria espaço para a subjetividade do investigador.

Dito de outro modo, os resultados obtidos pela ciência, segundo essa lógica, não dependeriam do pesquisador, uma vez que a verdade estaria no próprio objeto. Ou seja, a adoção dos procedimentos científicos, por si só, já assegurariam a neutralidade.

Ocorre, todavia, notadamente a partir de um olhar que privilegie a complexidade, que sobredita neutralidade é inexistente, vale dizer, não passa de um mito. E isso porque, assim como ocorre com as demais formas de saber, também na ciência suas reflexões e seus procedimentos são sempre parciais, existenciais, contextuais e, sobretudo, inter-relacionais.

\footnotetext{
17 Não apenas a objetividade lhe conferia essa possibilidade, mas também outras características, tais como a racionalidade, a sistematicidade e a verificabilidade (LAKATOS, 2010, p. 62).
} 
Nesta perspectiva, olhando o mesmo lugar do sujeito, mas tendo-se como base não o paradigma cientificista, mas a teoria da complexidade, observa-se que sujeito e objeto aparecem como as duas emergências últimas inseparáveis da relação sistema auto-organizador/ecossistema (MORIN, 2011, p. 39).

Contraria-se, assim, a lógica da ciência que se fundamentou na eliminação positivista do sujeito a partir da ideia de que os objetos, existindo independentes do sujeito, podiam ser observados e explicados como tais. Supera-se a ideia do sujeito que é dispensado precisamente por ser indescritível segundo os critérios do objetivismo e que, expulso da ciência, assume sua revanche na moral, na metafísica, na ideologia, local esse onde se elimina o objeto. O sujeito se desdobra no reino não ocupado pela ciência (MORIN, 2011, p. 41).

No paradigma da complexidade, tem-se que sujeito e objeto são inseparáveis. Vale dizer, só existe objeto em relação a um sujeito e só há sujeito em relação a um meio ambiente objetivo. São constitutivos um do outro, embora não sem brechas e incertezas, eis que ambos os conceitos são insuficientes e incompletas (MORIN, 2011).

\section{OS OBSTÁCULOS EPISTEMOLÓGICOS ENFRENTADOS E IMPOSTOS PELA TEORIA DA COMPLEXIDADE: UMA ANÁLISE A PARTIR DO DIREITO}

Demonstrou-se, acima, que a complexificação da vida e das relações sociais não foram acompanhadas pelo paradigma hegemônico científico, na medida em que sua racionalidade não permitiu o fornecimento de respostas de modo a atender às demandas atuais em sua plenitude.

Essa crise esgarçada, por sua vez, possibilitou o florescimento da teoria da complexidade, enquanto alternativa de superação do viés moderno e de sua racionalidade instrumental.

Esse processo, porém, encontra evidentes entraves de diversos matizes, dentre os quais, obstáculos epistemológicos. E isso porque, no modelo anterior, coube à ciência moderna não apenas a primazia da verdade, mas também o papel de protagonismo epistemológico como única forma de conhecimento credível. E são exatamente essas barreiras que se procura transpor para a emergência deste novo modelo.

De outro lado, essa nova perspectiva se apresenta, por si só, também como obstáculo, na medida em que demanda um esforço social ativo de internalização, ante as mudanças que provoca. 
Nota-se, portanto, a emergência de um paradigma que, ao passo que enfrenta obstáculos, também os impõe. Trata-se, pois, de uma tarefa duplamente dificultosa.

Desta feita, obstáculo epistemológico pode ser identificado como uma antirruptura (BACHELARD, 1996). Ela é interna quando advém daquilo que se encontra no próprio âmago do que se procura irromper, mas a sua própria racionalidade não permite, ou externa, quando uma racionalidade contraposta atua no sentido de manutenção do seu status quo.

Propõe-se, assim, a partir do olhar do campo jurídico, a análise de dois obstáculos epistemológicos, um no plano teórico externo enfrentado pelo paradigma da complexidade - qual seja, o positivismo jurídico -, e o outro, por sua vez, no plano prático interno, imposto por esse novo modelo - vale dizer, o pluralismo jurídico.

\subsection{O POSITIVISMO CIENTIFICISTA E O POSITIVISMO JURÍDICO COMO OBSTÁCULOS EPISTEMOLÓGICOS TEÓRICOS ENFRENTADOS PELO PARADIGMA DA COMPLEXIDADE}

Vem se demonstrando até então, a partir da construção teórica realizada, a maneira pela qual o positivismo cientificista representou evidente entrave à emergência do paradigma da complexidade. Oportuno, todavia, realizar-se delineamento teórico acerca do positivismo, demonstrando, ainda, como também o positivismo jurídico, no campo do direito, representa igual obstáculo para esse novo modelo.

Neste sentido, não apenas a ciência moderna, mas também o direito moderno estatal formam os pilares sobre os quais se fundou a modernidade. Deste modo, enquanto o primeiro tratou de informar os critérios de verdade e de falsidade para as explicações sobre a vida, o segundo regulou-a, dentro dos limites da legalidade e da ilegalidade.

Inclusive, a emergência do direito moderno estatal enquanto pilar fundador da modernidade foi possibilitada pela própria ciência moderna. E isso porque, enquanto o conhecimento científico é corolário do positivismo, o positivismo jurídico - enquanto concepção teórica predominante no direito moderno - também é resultado deste.

Esse positivismo cientificista, decorrente da racionalidade moderna e imperante no paradigma hegemônico, tem como característica a aspiração "à formulação de leis, à luz de regularidades observadas, com vista a prever o comportamento futuro dos fenômenos" (SANTOS, 2010b, p. 29). 
Em outras palavras, "um conhecimento baseado na formulação de leis tem como pressuposto metateórico a ideia de ordem e de estabilidade do mundo, a ideia de que o passado se repete no futuro" (SANTOS, 2010b, p. 30).

Observa-se, deste modo, que o projeto positivista tinha o propósito moderno arraigado em si mesmo, quer dizer, tratava-se de um projeto cuja pretensão era a libertação. Como assevera Galuppo (2005, p. 197), “o Positivismo é um projeto inerente à própria Modernidade: conhecer para dominar, e dominar para libertar. Ordem e progresso".

A concepção positivista tinha como base o estudo das ciências naturais, e, mais do que isso, acreditava num modelo universal dessas ciências, através de sua metodologia e seu caráter experimental, bem como uma marcante separação entre sujeito e objeto, cuja qual julgava imprescindível à própria realização da ciência, vale dizer, o devido afastamento entre o sujeito que conhece, neutro e alheio ao objeto a ser conhecido, como se não fosse parte do mesmo, ou não lhe interferisse de nenhum modo.

Baseava-se, assim, em critérios de cientificidade próprios e pretensamente rigorosos, sistemáticos e exatos, bem como com aspirações à imutabilidade e infalibilidade. Esses preceitos, inclusive, importados das ciências naturais, eram aplicados aos fenômenos sociais.

Evidenciou-se, todavia, conforme já demonstrado, as limitações e inadequações do modelo positivista, tendo o mesmo, via de consequência, passado a enfraquecer. São várias as razões, como, por exemplo: a diferença do objeto entre as ciências naturais e as ciências humanas; o alto grau de complexidade dos fatos humanos; a inegável influência exercida pelo pesquisador em sua ação sobre o objeto de estudo; a dificuldade de se atingir o "verdadeiro" ou leis universais, tendo em vista a mutabilidade do comportamento humano (DIONNE; LAVILLE, 1999).

E não poderia ser diferente, tendo em vista que nas ciências humanas, o sujeito é também objeto, vale dizer, é parte dele; daí a impossibilidade de sua neutralidade ou afastamento. Noutras palavras, o sujeito é, em realidade, objeto, assim como o objeto é, ao mesmo tempo, também sujeito. Rompe-se, assim, com essa dicotomia, o que contribui sobremaneira para o abalo do modelo positivista.

Ademais, somando-se a este rompimento, a própria ideia de determinismo dos resultados, ante a repetição do procedimento, é absolutamente questionável nas ciências humanas, assim como a 
própria experimentação, por si só, acerca dos fatos humanos, também já denota enorme grau de dificuldade.

Deste modo, as próprias ciências naturais passaram a se perceber limitadas tendo como pressupostos o positivismo, passando assim a questionar, ela própria, seus princípios de empirismo, sua ideia de lei, de determinismo, assim como sua regras de objetividade (DIONNE; LAVILLE, 1999), entre outros.

Não obstante a percepção de sua limitação e seu consequente enfraquecimento, o modelo positivista e sua pretensão de afastamento e de "pureza" científica, influenciou os diversos ramos do conhecimento, dentre os quais o direito. Advém daí, portanto, o positivismo jurídico; ou seja, a pretensão de cientificização do direito.

Essa ideia de cientificização do direito, inclusive, perpassou sobre a figura da autoridade capaz de direito o direito, a autoridade soberana. E tal constatação se liga umbilicalmente com a própria modernidade em si, bem como com a construção da sociedade moderna e dos Estados modernos, que avocaram para si o poder de dizer o direito como único válido, excluindo quaisquer outras fontes.

Deste modo, para o positivismo jurídico só é direito o que é dito - ou "posto", conforme expressão que melhor configura o positivismo - pela autoridade que tem o poder de dizê-lo, extirpando-se para fora dos limites da legalidade tudo o que não for colocado por este próprio poder.

Qualquer ordem pretensamente jurídica que não emane da figura do Estado, portanto, não é considerado como direito. E, mais, além do fato de que esse direito é válido a partir de posto, não cabendo ao seu intérprete valorar seu conteúdo - se bom ou ruim -, mas apenas aplicá-lo, "em função de uma suposta neutralidade axiomática, de um rigoroso experimentalismo e, ao mesmo tempo, de um tecnicismo formalista" (WOLKMER, 2000, p. 158), também havia um anseio de afastamento com outros ramos do conhecimento, em razão da própria influência positivista.

Em outras palavras, o positivismo jurídico é a ideia pela qual "o Positivismo pretende converter o conhecimento jurídico em ciência" (GALUPPO, 2005, p. 198). E essa conversão se daria a partir da observância de quatro características principais, quais sejam: a ficção de que a lei, enquanto objeto do conhecimento jurídico é autoexistente e que, por isso, pode ser controlado pelo homem; em segundo lugar, a neutralidade, ou seja, a ideia de que ao cientista do direito não compete atribuir juízo de valor 
à norma, mas apenas descrevê-la ${ }^{18}$; ainda, o compromisso metodológico da ciência do direito, no sentido de se adotar o modelo das ciências naturais como o adequado ao conhecimento jurídico; e, por fim, o raciocínio sistemático, numa ideia de harmonia com fulcro de regulação da vida humana (GALUPPO, 2005, p. 198).

Tércio Sampaio Ferraz Jr. (1980, p. 33-34), por sua vez, identifica duas características principais do positivismo jurídico. A primeira delas, a ausência de lacunas, ou seja, a ideia de um sistema fechado. Já a segunda - inserida na primeira -, a noção de que esse mesmo sistema fechado traz em si mesmo um método, quer dizer, um instrumento do próprio pensamento jurídico; o dogma da subsunção.

Em ambos os exemplos, o que se observa é que as características marcantes do positivismo jurídico operam na direção da redução da complexidade do direito, o que, num primeiro momento, parece adequado - afinal, quando se pensa em complexidade, associa-se à ideia de caos ou desordem -, mas que, em realidade, não o é, tendo em vista que a redução da complexidade do direito é, em última análise, a redução do próprio mundo.

Nota-se, portanto, que a proposta do positivismo jurídico, sobretudo nos dias atuais, tende a fracassar, embora não se negue, evidentemente, o seu valor, eficácia e funcionalidade durante o período em que informou a racionalidade jurídica. Todavia, tem-se que a mesma não responde mais às demandas da sociedade.

A própria ideia do direito como um sistema fechado, como aponta Ferraz Jr. (1980, p. 33), vai diametralmente de encontro à ideia de sistema aberto, inerente à teoria da complexidade, o que por si só já denota flagrante barreira epistemológica enfrentada pelo paradigma emergente.

Assim, se forja um direito de forma anacrônica e descontextualizada, não observando o aspecto social em que o mesmo se encontra inserido, como se a ele fosse alheio ou superior. Um direito que não enxerga a pluralidade das experiências do mundo e nega a complexidade das relações humanas, atuando ativamente em sentido contrário. Um fim em si mesmo, bastante por si só.

Cria-se, desta maneira, uma crise de legitimidade e um evidente obstáculo epistemológico teórico - que, por óbvio, reflete-se na prática jurídica -, tendo em vista que se tem um direito que não

\footnotetext{
${ }^{18}$ Daí a ideia positivista de separação entre direito e moral.
} 
atende mais às demandas sociais, e, mais, um direito que, muitas vezes e paradoxalmente, nega direitos ao não reconhecê-los, ou ao reconhecê-los como não direito.

Essa pretensão de transposição da lógica positivista para o mundo jurídico, através da cientificização do direito, trouxe consigo as disfunções a ela inerentes, influenciando-o de forma perversa, na medida em que o subjugou a trabalhar segundo seus próprios mecanismos, onde a dicotomia científica do verdadeiro/falso se converte no binômio legal/ilegal; lícito/ilícito.

Apresenta-se, assim, o direito enquanto influenciado pela vertente positivista, claro obstáculo epistemológico ao seu próprio reconhecimento como irmão siamês da complexidade, na medida em que impera sua pretensão cientificizante de redução da complexidade do real, enquadrando todo e qualquer caso, por mais múltiplo que possa se mostrar, dentro de uma "caixinha", a norma jurídica. Trata-se da famigerada subsunção do fato à norma, como se houvesse uma correspondência necessária entre ambos.

\subsection{O PLURALISMO JURÍDiCO COMO OBSTÁCULO EPISTEMOLÓGICO PRÁTICO IMPOSTO PELO PARADIGMA DA COMPLEXIDADE}

Se de um lado o positivismo jurídico se apresenta como entrave teórico enfrentado pelo paradigma da complexidade no que diz respeito à sua emergência, o pluralismo jurídico - enquanto concepção que encontra nele campo fértil -, se mostra como obstáculo imposto por este modelo à sua própria emergência.

A concepção de um pluralismo jurídico decorre do próprio pluralismo social e da pluralidade das relações humanas. Vale dizer, direito plural é corolário de uma sociedade plural, e esta, por sua vez, só pode decorrer de um paradigma que, da mesma forma, privilegie o pluralismo e o complexo.

Noutras palavras,

a crise do modelo normativo estatizante propicia, gradualmente, amplas possibilidades para o surgimento de orientações 'prático-teóricas' insurgentes e paralelas que questionam e superam o reducionismo dogmático-positivista representado pela ideologia centralizadora. Por consequência, repensar a questão do 'pluralismo' nada mais é do que a tentativa de buscar outra direção ou outro referencial epistemológico que atenda à modernidade na virada no século XX e nos primórdios do novo milênio [...] (WOLKMER, 2001, p. 170). 


\section{Quaestio Iuris}

vol. 13, no. 01, Rio de Janeiro, 2020. pp. 123-147 DOI: $10.12957 /$ rqi.2020.39955

Neste sentido, assim como o positivismo jurídico extrai seu arcabouço do positivismo, também o pluralismo jurídico advém do pluralismo. Assim, numa perspectiva mais generalista, tem-se que o pluralismo é aquele que se opõe ao monismo ${ }^{19}$.

Mas, assim como há diversos pluralismos, há também variadas formas de monismo, de modo que o projeto da modernidade é, portanto, sob diferentes aspectos monista e simplificador; vale dizer, tem como pretensão, por exemplo, uma única forma política (liberal-burguesa) e econômica (capitalista). Em sua vertente jurídica, por sua vez, o monismo jurídico se apresenta como pretensão de monopólio estatal da produção jurídica (WOLKMER, 2001, p. 25).

Deste modo, sendo, portanto, a contraposição do monismo, o pluralismo designa a "existência de mais de uma realidade, de múltiplas formas de ação prática e da diversidade de campos sociais com particularidade própria", ou, dito de outro modo, "envolve o conjunto de fenômenos autônomos e elementos heterogêneos que não se reduzem entre si” (WOLKMER, 2001, p. 171-172). Nega, então, a concepção de que existe apenas uma possibilidade credível para a compreensão dos fenômenos do mundo, primando pela diversidade dessas experiências.

Nesta perspectiva, conforme assevera Antônio Carlos Wolkmer (2001), o pluralismo pode ser verificado além do âmbito jurídico, também em âmbitos político, sociológico, filosófico, econômico ou ideológico, repousando, suas concepções, não no enfraquecimento do poder do Estado, senão no fortalecimento das demais instâncias sociais de poder.

Dito de outra forma, o que se pretende com o pluralismo - notadamente o jurídico -, é o combate à centralização político-jurídica nas mãos do Estado, reconhecendo-se, sem qualquer juízo de valor, outras fontes possíveis dessa produção. Tem-se, assim, que o pluralismo não denota desorganização ou ausência do Estado, muito menos se caracteriza como campo de batalha, mas é a aceitação de "interesses opostos e costumes diversos" (WOLKMER, 2001, p. 181).

No que atine especificamente ao pluralismo jurídico, o que se precisa ter em mente de maneira clara, é o que o Estado não é a fonte única e exclusiva de todo o direito (WOLKMER, 2001, p. 183), senão apenas uma dessas fontes. Ou seja, falar-se em pluralismo jurídico é discutir, em realidade, as fontes do direito, e um olhar mais apurado permite perceber que a escolha do Estado como sua fonte

\footnotetext{
${ }^{19}$ Entende-se monismo a partir da ideia de unidade. Vale dizer, a partir da concepção de uma única possibilidade credível para a compreensão dos fenômenos do mundo. Há, assim, o monismo em sua vertente política, econômica, entre outras; ou seja, há, assim, através da ideia monista, a difusão de uma única esfera política possível, por exemplo, reduzindo-se a realidade a ela.
} 
principal e exclusiva, é nada mais que uma opção moderna, em razão do próprio modo como o mesmo se consolidou.

Ocorre que esse mesmo Estado, a partir de sua criação e de seu fortalecimento, arvorou-se na prerrogativa de tolher quaisquer outras fontes, colocando-se como única possível, relegando ao campo da ilegalidade todas as demais fontes pretensamente jurídicas.

Nesta perspectiva, portanto, visando um enquadramento teórico-conceitual, o pluralismo jurídico ocorre quando "no mesmo espaço geopolítico vigora (oficialmente ou não) mais de uma ordem jurídica" (SANTOS, 1987, p. 46); admitindo-se, também, a lição de Antônio Carlos Wolkmer (2001, p. 219), para quem se designa o pluralismo jurídico "como a multiplicidade de práticas jurídicas existentes num mesmo espaço sócio-político, interagidas por conflitos ou consensos, podendo ser ou não oficiais e tendo sua razão de ser nas necessidades existenciais, materiais e culturais”.

Pormenorizando os sobreditos conceitos, há que se entender o pluralismo jurídico a partir da percepção da multiplicidade das fontes do direito, reconhecendo-se a diversidade dos atores sociais para além do olhar hegemônico cientificista e sua racionalidade que desconsidera esses sujeitos.

Nota-se, portanto, que o pluralismo jurídico encontra campo fértil de desenvolvimento no paradigma da complexidade e é exatamente nesse contexto que ele se coloca como um obstáculo epistemológico imposto por esse modelo, na medida em que nega a primazia do Estado na produção do direito.

E não poderia ser diferente, pois essas novas fontes, sendo ou não reconhecidas pelo Estado, vigoram, conflitivamente ou não, no mesmo instante temporal e no mesmo espaço geográfico ${ }^{20}$, regulando a vida dos diferentes grupos sociais, de modo que a fundamentação acerca desse direito emergente da sociedade, bem como seus contornos epistemológicos, é dotada da complexidade inerente aos mesmos.

Desta feita, portanto, o maior obstáculo epistemológico que o paradigma da complexidade impõe ao buscar estabelecer o pluralismo jurídico, atine ao reconhecimento desses novos direitos, pois, se de um lado não cabe ao Estado esse papel, do outro, não se pode negar seu protagonismo.

${ }^{20}$ Trata-se, portanto, de uma coexistência espacial e temporal, conflitiva ou não. 
Explicando em pormenores, o Estado se impõe como única fonte possível do direito, impondo sua "vontade jurídica" sobre todas as formas de relações sociais, independentemente de suas realidades e especificidades. E o próprio Estado, em razão do alargamento de seu protagonismo na modernidade, se arvora no papel de dizer o legal e o ilegal, impondo, permitindo ou tolerando formas jurídicas dentro dos limites do que considera como "direito oficial".

Assim, dizer que a existência jurídica do pluralismo jurídico independe da posição do Estado frente a ele seria não atentar ou mesmo negligenciar a realidade do estágio evolutivo humano, notadamente o social, e seus limites. E isso porque, sabe-se que o Estado possui um protagonismo que não pode ser simplesmente ignorar.

Noutro sentido, porém, não é possível se considerar que num paradigma da complexidade, em que preze pela pluralidade, o Estado ocupe esse espaço privilegiado ou cumpra com esse papel de soberano, "reconhecedor" dos direitos e das pluralidades, uma vez que isso seria recair, novamente, no monismo jurídico. Ou seja, depender do aval estatal é negar o pluralismo jurídico.

É esta, pois, uma grande barreira epistemológica prática imposta pelo paradigma da complexidade, eis que caminha frontalmente de encontro ao estabelecido pela racionalidade dominante, de modo que a conformação de ambas se apresenta dificultosa, não havendo resposta pronta e acabada para este problema.

O que se espera, apenas, é que se caminhe para um paradigma plural - o que demanda, além de tempo, um esforço epistemológico, social, político, etc. -, em que seja possível a sua emergência e que isso se compatibilize de alguma maneira com a existência estatal, ainda que de forma conflitiva ${ }^{21}$ - numa coexistência harmonicamente conflituosa -, de modo que ainda não se tem uma resposta pronta, acabada e definitiva de como isso pode acontecer, sabendo apenas haver de se construir essa convivência.

\section{CONSIDERAÇÕES FINAIS}

O presente estudo foi iniciado, já na sua introdução, com a construção de objetivos específicos e um problema, como fio-condutor - que serviram de força motriz e combustível ao fôlego

\footnotetext{
${ }^{21}$ Conflitividade não é sinônimo de impossibilidade de coexistência, ao contrário, é condição inerente à vida em sociedade e, se assim o fosse, a mesma não existiria. O próprio pluralismo jurídico é por si só conflituoso, eis que opera imerso a antagonismos e interesses contrapostos.
} 
teórico dispensado na pesquisa. Assim, oportuno sejam realizadas análises finais acerca das perguntas, sem pretender esgotar o tema, para que fique claro os caminhos que foram abertos a partir da investigação.

Viu-se, que a racionalidade moderna se pautou na forma de saber científica. Coube, assim, à ciência moderna não apenas a primazia da verdade, mas também o papel de protagonismo epistemológico como única forma de conhecimento credível, tendo esse cientificismo se espraiado para outras áreas do saber, tais como o direito.

Ocorre, todavia, que se verificou uma crise do paradigma positivista cientificista, na medida em que seu avanço esgarçou suas próprias limitações e insuficiências, de modo que, para superá-la, Morin (2011), propõe a passagem do paradigma simplificador, mutilador da realidade - eis que limitado -, para o paradigma da complexidade.

E isso porque esse paradigma emergente operaria de forma a substituir o raciocínio moderno - disjuntiva e reducionista -, para uma racionalidade que contemple em seu bojo o paradoxo do uno e do múltiplo, um inserido dentro do outro, constituindo-se mútua e heterogeneamente, através de uma inseparável associação. E é exatamente a teoria da complexidade a ferramenta que permitiria essa transição paradigmática.

Finalmente, objetivando encerrar a análise deste estudo, cumpre-se tecer breves comentários acerca da proposta principal da pesquisa, vale dizer, verificar quais seriam os obstáculos epistemológicos - teóricos e práticos - impostos e enfrentados pela teoria da complexidade no paradigma emergente, tendo como lente de observação o direito.

Neste sentido, se analisou o positivismo jurídico enquanto obstáculo teórico enfrentado pelo paradigma da complexidade, na medida em que opera na redução da complexidade do direito, que, em última análise, é a redução da complexidade do próprio mundo, não respondendo, assim, às demandas sociais, uma vez que se forja como um direito anacrônico e delas descontextualizado.

Já enquanto obstáculo epistemológico prático imposto pelo paradigma emergente se examinou o pluralismo jurídico. Este, por sua vez, se coloca como antirruptura, pois nega a primazia do Estado na produção do direito, o que se mostra dificultoso, tendo em vista que não se pode negar o protagonismo estatal nessa produção, bem como, noutro sentido, deixa-la exclusivamente ao seu cargo 
seria negar o próprio pluralismo jurídico. Reside ai, portanto, a grande barreira epistemológica, vale dizer, a conformação conflituosa de ambas as perspectivas.

Trataram-se, pois, de dois obstáculos epistemológicos escolhidos para análise, dentre tantos outros possíveis, enfrentados e impostos pelo paradigma da complexidade, enquanto modelo emergente que pretende informar as ações na realidade contemporânea.

\title{
POSITIVISM, LEGAL PLURALISM AND THE EMERGING PARADIGM: THE THEORY OF COMPLEXITY AND ITS EPISTEMOLOGICAL OBSTACLES
}

\begin{abstract}
The present article intends to investigate what would be the theoretical and practical obstacles, imposed and faced by the theory of complexity in the emerging paradigm, having as a locus of observation the look from the law. Therefore, it starts from the analysis of the paradigmatic transition experienced between modernity and the emerging model, verifying, from the examination of theoretical references, the scientific paradigm and the context of the emergence of complexity theory, as well as the emergence of the "complex" and the need to break with the paradigm in crisis, also outlining the general aspects of the theory that underlies this passage. It is proposed, then, to contribute to the debate, investigating theoretically and dialectically, the relationship between law and rationality and the paths that are drawn from there, to conclude by the existence of two obstacles: legal positivism, as a theoretical obstacle, operating in reducing the complexity of the law; and, legal pluralism, as an epistemological obstacle, denying the primacy of the State in legal production. The formation of both obstacles is the epistemological barriers that arise in the emergence of the emerging paradigm.
\end{abstract}

Keyword: complexity theory - emerging paradigm - positivism - legal pluralism - epistemological obstacles

\section{REFERÊNCIAS}

BACHELARD, Gaston. A formação do espírito científico: contribuição para uma psicanálise do conhecimento. Rio de Janeiro: Contraponto, 1996.

DIONNE, Jean; LAVILLE, Christian. A construção do saber: manual de metodologia da pesquisa em ciências humanas. Porto Alegre: Artmed, 1999. 
FERRAZ JR., Tercio Sampaio. A ciência do direito. 2. ed. São Paulo: Atlas, 1980.

GALUPPO, Marcelo Campos. A epistemologia jurídica: entre o positivismo e o pós-positivismo. In: Revista do Instituto de Hermenêutica Jurídica - crítica à dogmática: dos bancos acadêmicos à prática dos tribunais. Vol. 01, $\mathrm{n}^{\mathrm{o}}$ 03, Porto Alegre: IHJ, 2005.

KUHN, Thomas S. A estrutura das revoluções científicas. São Paulo: Perspectiva, 1975.

LAKATOS, Eva Maria; MARCONI, Maria de Andrade. Fundamentos de metodologia científica. 7. ed. São Paulo: Atlas, 2010.

MORIN, Edgar. Introdução ao pensamento complexo. 4. ed. Porto Alegre: Sulina, 2011.

SANTOS, Boaventura de Sousa. A crítica da razão indolente: contra o desperdício da experiência. 8. ed. São Paulo: Cortez, 2011.

. A gramática do tempo: para uma nova cultura política. 3. ed. São Paulo: Cortez, 2010.

. Conhecimento prudente para uma vida decente: um discurso sobre as ciências revisitado.

2. ed. São Paulo: Cortez, 2006.

. Notas sobre a história jurídico-social de Pasárgada. In: SOUZA JÚNIOR, José Geraldo de $\overline{\text { [Org.]. }}$ O direito achado na rua. Brasília: UnB, 1987.

. Para além do pensamento do pensamento abissal: das linhas globais a uma ecologia de saberes. In: Revista Crítica de Ciências Sociais, nº 78, Outubro, 2007.

. Renovar a teoria crítica e reinventar a emancipação social. São Paulo: Boitempo, 2007 b.

Um discurso sobre as ciências. 7. ed. São Paulo: Cortez, 2010 b.

WOLKMER, Antônio Carlos. Ideologia, Estado e Direito. 3. ed. rev. e ampl. São Paulo: Revista dos Tribunais, 2000.

. Introdução ao pensamento jurídico crítico. 4. ed. São Paulo: Saraiva, 2002. 
Quaestio Iuris

vol. 13, nº. 01, Rio de Janeiro, 2020. pp. 123-147 DOI: $10.12957 /$ rqi.2020.39955

Pluralismo jurídico: fundamentos de uma nova cultura no direito. 3. ed. rev. e atual. São Paulo: Alfa Omega, 2001.

Trabalho enviado em 05 de fevereiro de 2019

Aceito em 15 de maio de 2020 